\title{
Stochastic Simulation of River Water Quality Risk assessment under Coupling Effect of Reclaimed Water Recharge and Inner Source Release
}

\author{
Han Yan, Zhihong Zou* \\ School of Economics and Management \\ BeiHang University \\ Beijing, China \\ E-mail: yanhannn@163.com
}

\begin{abstract}
A river water quality model under a coupling effect of reclaimed water recharge and inner source release is constructed based on a one-dimensional steady river water quality model. In order to solve problems that triangular fuzzy numbers are not suitable for data sets having flat representation and no obvious peak values, the fuzzy number operations are not rigorous and operation processes are comparatively complicated and the like, trapezoidal fuzzy numbers were adopted for substituting triangular fuzzy numbers, and used the Monte-Carlo method to simulate the trapezoidal fuzzy numbers for transforming the operations of trapezoidal fuzzy numbers and their functions into the conventional operations of real numbers, and constructed the WQRA-SSTFN model. Case study shows that calculation results of risk values are stable and reliable.
\end{abstract}

Keywords- Reclaimed water recharge; inner source release; trapezoidal fuzzy number; stochastic simulation; risk assessment

\section{INTRODUCTION}

Taking reclaimed water as a water recharge source has become a common tendency both in and abroad. The reclaimed water generated by processing sewage is the main water recharge source of many rivers, especially rivers in the northern area in China[1]. The substance elements in the reclaimed water are complicated. The reclaimed water commonly contains poisonous and harmful contaminants such as endocrine disruption living beings in low dosage, carcinogenic, teratogenic and mutagenic matter and the like and threatens the health of the river ecosystem directly or potentially. In a river pollution treatment process, pollution of bottom mud is also a significant element influencing the water quality of rivers. Poisonous and harmful substance is easy to accumulate in the bottom mud of rivers. The sediment will be released again under an appropriate condition through physical, chemical and biological exchange effects with water body covering in the above, and becomes an important inner pollution source influencing the water quality of rivers[2]. Therefore, exploring the water quality decay regulation under a coupling effect of the recharge of the reclaimed water and the inner source release from the sediment and evaluating the water quality risks attach great importance for the scientific regulation and management of water quality states of rivers.

Some studies[3-6] have proved that parameters of river hydrology, water quality and hydraulic condition and hydrogeological parameters are basically random variables subjecting to normal distribution or logarithmic normal distribution. In recent years, fuzzy mathematical method has been widely applied to research and practices for reducing uncertainties of a system. The fuzzy mathematical method describes the gradual change and the fuzziness of pollution condition through membership degree functions, thereby improving the accuracy and reliability[7-8] of an evaluation result. Triangular fuzzy number processing method has comparatively good applicability in conditions having insufficient data information or having data without high precision. Triangular fuzzy number processing method has been applied to groundwater environment risk evaluation[9] and evaluationof heavy metal pollution of soil successively[10]. However, because of limitation of the membership degree of triangular fuzzy number itself, the most probable value of the triangular fuzzy number is only a point. Triangular fuzzy number will bring comparatively large simulation errors for parameters sets having comparatively flat distribution integrally and no obvious peak value in practice and even disturb the final decision. Trapezoidal fuzzy number gives out a good solution to the above problems on the basis of inheriting the advantages of the triangular fuzzy number. In addition, there is a major problem on both triangular fuzzy number and trapezoidal fuzzy number in the application: the current fuzzy number operation on multiplication, division and function is not rigorous and the realization process is comparatively complicated.

Therefore, on the basis of river water quality model subjected to coupling effect of reclaimed water recharge and sediment release, the Monte-Carlo method was applied to simulate the trapezoidal fuzzy numbers for transforming the operations of trapezoidal fuzzy numbers and their functions into the conventional operations of real numbers, and then a method, namely WQRA-SSTFN, coupling the stochastic simulation with trapezoidal fuzzy numbers for risk assessment of water quality was established.

\section{WQRA-SSTFN MODEL} model:

There are three steps to construct the WQRA-SSTFN

Step1: The expression of fuzzy variable by trapezoidal fuzzy number. Defines a trapezoidal fuzzy number $\tilde{A}=\left(a_{1}, a_{2}, a_{3}, a_{4}\right)$, wherein $a_{1}, a_{2}, a_{3}$ are real numbers and 
$a_{1} \leq a_{2} \leq a_{3} \leq a_{4}$. A membership function corresponding to the fuzzy number $\tilde{A}$ is[11-12]

$$
\mu_{\tilde{A}}(x)=\left\{\begin{array}{l}
0, x<a_{1} \\
\left(x-a_{1}\right) /\left(a_{2}-a_{1}\right), a_{1} \leq x \leq a_{2} \\
1, a_{2} \leq x \leq a_{3} \\
\left(a_{4}-x\right) /\left(a_{4}-a_{3}\right), a_{2} \leq x \leq a_{3} \\
0, x>a_{4}
\end{array}\right.
$$

$a_{1}$ and $a_{4}$ are a lower limit and a higher limit of the trapezoidal fuzzy number $\tilde{A}$ respectively.

$a_{2} \leqslant x \leqslant a_{3}$ is a relatively most probable value range. When $a_{2}=a_{3}$, the trapezoidal fuzzy number converts to a triangular fuzzy number. Thus, the triangular fuzzy number could be a special form of the trapezoidal fuzzy number in the sense.

Step2: Stochastic simulation for the trapezoidal fuzzy number. According to the (2), we can easily get the probability density function of $\tilde{A}$, from which we can get the stochastic simulation formula for variable $x$ by inverse transformation method,

$$
x=\left\{\begin{array}{c}
\frac{a_{1}+\sqrt{r\left(a_{3}+a_{4}-a_{1}-a_{2}\right)\left(a_{2}-a_{1}\right)} \quad, r<\frac{a_{2}-a_{1}}{\left.a_{3}+a_{4}-a_{1}-a_{2}\right)+a_{1}+a_{2}}}{2}, \frac{\left(a_{2}-a_{1}\right)}{a_{3}+a_{4}-a_{1}-a_{2}} \leq r<\frac{2 a_{3}-a_{1}-a_{2}}{a_{3}+a_{4}-a_{1}-a_{2}} \\
a_{4}-\sqrt{(1-r)\left(a_{3}+a_{4}-a_{1}-a_{2}\right)\left(a_{4}-a_{3}\right)}, r \geq \frac{2 a_{3}-a_{1}-a_{2}}{a_{3}+a_{4}-a_{1}-a_{2}}
\end{array}\right.
$$

where $x$ is uniformly distributed random number between zero and one.

Large amounts of random number between 0 and $1, r_{1}, r_{2}, \cdots, r_{N}$, can be generated by computer program, then bring these random number into (2) to get the simulation results, $x_{1}, x_{2}, \cdots, x_{N}$, for the variable $x$. So the operations of trapezoidal fuzzy numbers and their functions are transformed into the conventional operations of real numbers. $N$ is the frequency of simulation experiments 。

Step3: Risk assessment of river water quality. Suppose $z$ is the value of river water quality, $z_{c}$ is the control limit value of river water quality, then the risk of river water quality can be defined as

$$
P_{z}=P\left(z \geqslant z_{c}\right)
$$

where $P()$ is the probability function of the event ' $z \geqslant z_{c}$ '.

According to the simulation method in Step 2, we can the random simulation sequence $\left\{z_{1}, z_{2}, \cdots, z_{N}\right\}, N$ is the frequency of simulation experiments 。Assume that $m_{z}$ is the number that the value of water quality in sequence $\left\{z_{1}, z_{2}, \cdots, z_{N},\right\}$ is more than the control limit value $z_{c}$, the risk of river water quality can be estimated as

$$
P_{z}=m_{z} / m \text {. }
$$

\section{SIMULATION MODEL OF RIVER WATER QUALITY}

Supposes that the mixture of reclaimed water entering into river and river water is complete physical mixture, reclaimed water realizes pure mixture and dilution of river water. At the moment, reclaimed water recharged at $x_{i}$ section mixes with river water at $x_{i}$ section. The contaminant concentration of mixed water flowing to $x_{i}$ section in downstream equals to the water quality formed in mixture effect on $x_{i}$ section after independent decay. If there are $m$ recharging points, a river water quality model under the coupling effect of reclaimed water recharge and sediment release can be obtained according to a conservation principle and by utilizing a mixture dilution model[13]:

$$
C(x)=\frac{1}{1+\sum_{i=1}^{m} \beta_{i}}\left\{C_{s} \exp \left[-\left(k_{1}+k_{2}\right) x / u\right]+\sum_{i=1}^{m} \beta_{i} C_{r}\left(x_{i}\right) \exp \left[-k_{1}\left(x-x_{i}\right) / u\right]\right\}
$$

where, $x$ is the distance of two cross sections (m); $u$ is the average velocity of water flow between the two cross sections $(\mathrm{m} / \mathrm{s}) ; \beta_{\mathrm{i}}=q\left(x_{i}\right) / Q$ is the ratio of unit discharge $q\left(x_{i}\right)$ and a flow $Q$, and is used for indicating the reclaimed water recharge strength relatively to the flow of the river; $C(x)$ is the contaminant concentration at $x$ cross section $(\mathrm{mg} / \mathrm{L}) ; C_{s}$ is river contaminant concentration in the initial section $(\mathrm{mg} / \mathrm{L}) ; C_{r}$ is contaminant concentration in recalimed water; $k_{1}$ is decay velocity $(1 / \mathrm{d}) ; k_{2}$ is sediment release velocity $(1 / \mathrm{d})$.

\section{CASE STUDY}

A large amount of contaminants settle on the bottom part of the river bed of an influent of the south bank of Hai River in China since the water is seriously polluted, the water quality is severely poor and the biological environment is deteriorating day by day in the past years. Along with improvement of the water contaminant control in a catchment area, the water quality of the river is recovered gradually. Therefore, the sediment release becomes a key influencing factor on the water quality again. The river is lack of ecological water for a long term and the land-and-water ecological system of the river has degenerated severely. The value functions of river ecological service has not been performed effectively and prior river cultural landscapes also exist in name only. Utilizing reclaimed water to supplement ecological water has become an effective measurement for relieving ecological crisis and the reclaimed water has become the main supplement water source of the area. Now a segment of river which is of a length of about $50 \mathrm{~km}$ without obvious point source pollution discharging, and the (5) is adopted for simulating the decay regulation of contaminant $\left(\mathrm{COD}_{\mathrm{Mn}}\right)$ in the river segment.

According to sampling material and experience in aspects of hydrology, water quality and the like, one reclaimed water recharge point $(m=1)$ is arranged through the river segment and a distance between a recharge section and an initial section is $3 \mathrm{~km}$. The basic data of each trapezoidal fuzzy parameter are shown as follows,

$$
\begin{gathered}
\tilde{u}=(0.44,0.5,0.55,0.6), \tilde{\beta}=(0.18,0.2,0.22), \\
\tilde{C}_{r}=(12.99,24.3,26.5,37.01), \tilde{C}_{s}=(11.5,16.2,18.3,23.5),
\end{gathered}
$$




$$
\tilde{k}_{1}=(0.33,0.45,0.47,0.6), \tilde{k}_{2}=(-0.14,-0.12,-0.11,-0.08)
$$

Suppose water quality control limit value is $15 \mathrm{mg} / \mathrm{L}$, and a section $x=15 \mathrm{~km}$ is adopted as a control section. Trapezoidal fuzzy numbers of $\tilde{u}, \tilde{\beta}, \tilde{C}_{r}, \tilde{C}_{s}, \tilde{k}_{1}, \tilde{k}_{2}$ can be simulated respectively by using the calculation method of step 2. A simulation sequence of $\tilde{C}(x)$ can be obtained by (5) and an estimation value of water quality risk can be obtained by (4). Results are shown in table 1 .

Table1 shows that the calculation value of WQRASSTFN is in convergence when the experiment frequncy is increased to 50000 . The mean value, the minimum value and the maximum value of contaminant concentration of control section are 16.60, 10,69 and $22.94 \mathrm{mg} / \mathrm{L}$, respectively. The estimation value of water environment risk is 0.771 .In order to analyze the relationship between the recharge intensity $\beta$ and the risk, let $\beta$ be fixed value $0.1,0.2, \quad 0.3$ and 0.4 , respectively, the corresponding estimation value of risk by WQRA-SSTFN is 0.681 , $0.773,0.836$ and 0.875 , which explains that the water quality is lowered and water quality risk is increased obviously along with the increase of the reclaimed water recharge intensity since the contaminant concentration in recharged reclaim water is higher than that in river.In order to analyze the sensitivity of the model, all fuzzy parameters can a variation of $\pm 5 \%, \pm 10 \%, \pm 20 \%, \pm 30 \%$ and $\pm 50 \%$ based on original value. The corresponding risk values are converged to be $0.765,0.760,0.753,0.745$ and 0.726 , which shows that the calculation of WQRA-SSTFN is comparatively stable.

\section{CONCLUSION}

In this paper, a river water quality model under a coupling effect of reclaimed water recharge and inner source release was constructed based on a one-dimensional steady river water quality model. This paper proposed to replace triangular fuzzy number with trapezoidal fuzzy number and use the Monte-Carlo method to simulate the trapezoidal fuzzy numbers for transforming the operations of trapezoidal fuzzy numbers and their functions into the conventional operations of real numbers, and construct the

\begin{tabular}{ccccc}
\multicolumn{2}{c}{ TABLE 1 Results of the water quality risk assessment } & Unit: $\mathrm{mg} / \mathrm{L}$ \\
\cline { 2 - 3 } Frequncy & \multicolumn{3}{c}{ Contaminant concentration of the control } \\
& Mection & Risk \\
\cline { 2 - 3 } 1000 & 16.65 & 10.87 & 22.57 & 0.782 \\
10000 & 16.61 & 10.66 & 22.56 & 0.774 \\
30000 & 16.59 & 10.82 & 22.87 & 0.771 \\
50000 & 16.60 & 10.69 & 22.94 & 0.771 \\
\hline
\end{tabular}

WQRA-SSTFN model. Case study shows that calculation results of risk values are stable and reliable.

\section{ACKNOWLEDGMENT}

This work is supported by the National Natural Science Foundation of China (No. 41071322 and 71031001).

\section{REFERENCES}

[1] M. A. Shannon, P. W. Bohn and M. Elimelech. "Science and technology for water purification in the coming decades," Nature, 2008, pp. 1038-1046

[2] K. Zhang. Research of Contaminated Sediments Effect on Overlying Water Quality. Shanghai, Shanghai University, 2011

[3] W. S. Luo and X. Y. Song. Water Environment Analysis and Prediction. Wuhan, Wuhan university press, 2000

[4] D. P. Loucks and W. R. Lynn. "Probabilistic models for predicting stream quality,” Water Resources Research, vol. 32, 1996, pp. 593605

[5] M. Stefano and G. Elisabetta. "Water quality modeling for small river basins,” Environmental Modelling \& Software, vol. 23, 2008, pp. 451-463

[6] L. C. Shu, Y. S. Zhu and Q. Y. Sun. "Risk analysis of groundwater allowable withdrawal evaluation,” Journal of Hydraulic Engineering, Mar. 2000, pp. 77-81

[7] L. F. Zhou, Z. Zhao, J.Z. Sun and X. G. Xing. “Assessment on Water Quality of Hun River Based on Fuzzy Pattern Recognition,” Research of Soil and Water Conservation, vol. 19, 2012, pp. 163-166

[8] Q. Z. Sun, S. Y. Zang and N. N. Zhang. "Pollution Evaluation of Heavy Metals in Lake Water Based on Fuzzy Comprehensive Assessment,” Environmental Engineering, vol. 30, 2012, pp. 111-115

[9] J. L, Jin, L. Liu, M. W. Wang, R. Z. Li and Y. L. Zhou. "Comprehensive Risk Assessment Method for Groundwater Environment System Based on Stochastic Simulation and Triangular Fuzzy Numbers,” Scientia Geographica Sinica, vol. 31, 2011, pp. 143-147

[10] F. Li, J. H. Huang, G. M. Zeng, X. J. Tang, X. Z. Yuan and J, Liang, et al. "An integrated assessment model for heavy metal pollution in soil based on triangular fuzzy numbers and chemical speciation of heavy metal,” Acta Scientiae Circumstantiae, vol. 32, 2012, pp. 432439

[11] L. O. David and D. S. Wu. "Simulation of fuzzy multiattribute models for grey relationships," European of Journal of Operational Research, vol. 175, 2006, pp. 111-120

[12] E. G. Ronald and E. Y. Rebort. "Analysis of the error in the standard approximation used for multiplication of triangular and trapezoidal fuzzy numbers and the development of a new approximation," Fuzzy Sets and Systems, vol. 91, 1997, pp. 1-13

[13] Y. S. Lu and Z. W. Ma. Environmental assessment. Shanghai, Tongji University Press, 1990 